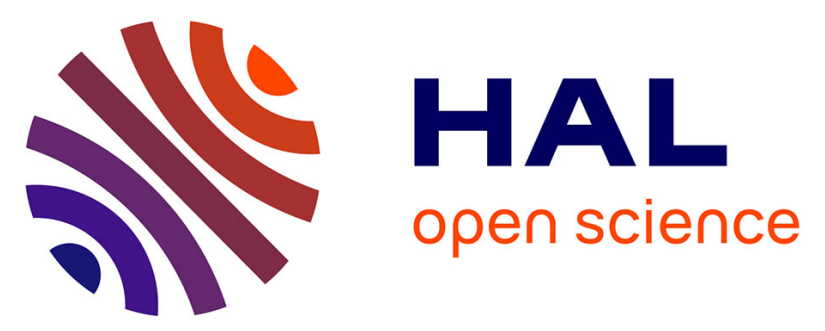

\title{
Impact of Motivational Climates on Claimed Self-Handicapping Strategies: Illustration in Tropical Environment
}

Guillaume R. Coudevylle, Stéphane Sinnapah, Cédric Charles-Charlery, Michelle Baillot, Olivier Hue

\section{To cite this version:}

Guillaume R. Coudevylle, Stéphane Sinnapah, Cédric Charles-Charlery, Michelle Baillot, Olivier Hue. Impact of Motivational Climates on Claimed Self-Handicapping Strategies: Illustration in Tropical Environment. Journal of Applied Sport Psychology, 2015, 27 (4), pp.384-397. 10.1080/10413200.2015.1014975 . hal-01343261

\section{HAL Id: hal-01343261 https://hal.univ-antilles.fr/hal-01343261}

Submitted on 8 Jan 2018

HAL is a multi-disciplinary open access archive for the deposit and dissemination of scientific research documents, whether they are published or not. The documents may come from teaching and research institutions in France or abroad, or from public or private research centers.
L'archive ouverte pluridisciplinaire HAL, est destinée au dépôt et à la diffusion de documents scientifiques de niveau recherche, publiés ou non, émanant des établissements d'enseignement et de recherche français ou étrangers, des laboratoires publics ou privés. 
Impact of Motivational Climates on Claimed Self-Handicapping Strategies: Illustration in Tropical Environment

Guillaume R. Coudevylle ${ }^{1}$, Stéphane Sinnapah ${ }^{1}$, Cédric Charles-Charlery, Michelle Baillot, and Olivier Hue

University of French West Indies, France

Author Note

All authors are at University of French West Indies, Department of Sport Sciences, Laboratory ACTES (EA 3596), Pointe-à-Pitre (France). 


\begin{abstract}
The purpose of the present study was to quantitatively and qualitatively examine whether claimed self-handicapping is increased in a performance motivational climate (PMC) compared with a mastery motivational climate (MMC) within a strictly controlled tropical environment. Participants completed measures of self-handicapping using open-ended questions before a physical test. The analyses revealed that (a) participants who engage in self-handicapping strategy were more numerous, (b) the number of self-handicap reported self-handicap score were greater, (c) participants who engage in self-handicapping strategy reported more impediments in the PMC as compared with MMC. Information about the nature of self-handicapping claims is also provided.
\end{abstract}

Keywords: claims, mastery climate, performance climate, tropical environment 
Impact of Motivational Climates on Claimed Self-Handicapping Strategies: Illustration in Tropical Environment

People who are preparing for a major event or assessment sometimes use specific strategies to protect themselves against a future failure or enhance their standing in the case of success. For instance, before performing an evaluated task, an individual may drink an alcoholic beverage or complain of fatigue, illness or adverse conditions. Berglas and Jones (1978) first described these behaviors and statements as "self-handicapping strategies." These authors defined self-handicapping as "... any action or choice of performance setting that enhances the opportunity to externalize (or excuse) failure and to internalize (reasonably accept credit for) success" (p. 406). If a self-handicapping person performs poorly, then the failure can be attributed to a performance impediment rather than the person's ability or competence. And if the self-handicapping person performs well, then the person creates the impression of being especially competent and talented, because success was achieved despite impediments. In addition, these individuals may also internalize the increased perceptions of competence (see Tice, 1991). Self-handicapping involves making claims or engaging in behaviors before an evaluated performance to excuse a possible failure or to make a success more gratifying (see Hirt, Deppe, \& Gordon, 1991; Leary \& Shepperd, 1986).

It has been amply documented that people's behaviors and claims are under multiple influences. The perception of a threatening situation may be one of the most powerful potential influences, as some authors have shown that people have a tendency to modulate their behaviors (Berglas \& Jones, 1978) and claims (Snyder \& Smith, 1982) in order to protect themselves. Moreover, Finez and Sherman (2012) tested the relationship between athletes' engagement in claimed self-handicapping and trait self-esteem. They showed that athletes with low physical self-esteem claim more handicaps than those with high physical 
self-esteem. They also showed that self-affirmed athletes have decreased levels of claimed self-handicapping.

\section{Motivational Climates Influence Claimed Self-Handicapping}

Self-handicapping strategies can also be influenced by the motivational climate (Coudevylle, Martin Ginis, Famose, \& Gernigon, 2009; Kuczka \& Treasure, 2005; Ntoumanis, Thøgersen-Ntoumanis, \& Smith, 2009; Standage, Treasure, Hooper, \& Kuczka, 2007). The concept of motivational climate (Ames, 1992) refers to the saliency of mastery (task) and performance (ego) cues in an achievement setting and is derived from achievement goal theory (Ames, 1984; Dweck, 1986; Nicholls, 1989). According to this theory, the demonstration of ability is the goal of action in achievement settings. In a mastery-oriented motivational climate, evaluations of one's performance are self-referenced and success is defined as mastering a task. In contrast, in a performance-oriented motivational climate, performance evaluations are based on social comparisons and success is defined in terms of out-performing others (Ames \& Archer, 1988).

Only two studies have experimentally manipulated motivational climates to examine the effects on claimed self-handicapping (Coudevylle et al., 2009; Standage et al., 2007). Within a skill test, Coudevylle and colleagues showed that male basketball players used more claims self-handicaps in the condition of PMC than in the condition of MMC. In the context of a physical education class, Standage and his colleagues found that adolescent students reported more self-handicaps before performing an endurance-running task in a performanceoriented motivational climate than in a task-oriented motivational climate. According to these authors, the adolescent students exposed to performance-involving cues become preoccupied with their comparative ability (i.e., not appearing unable or appearing able), making selfhandicapping more likely as a self-protective strategy to deflect attention away from a lack of ability (Midgley \& Urdan, 2001; Urdan \& Midgley, 2001). Although PMC is known to 
stimulate self-handicapping, there seems to be a major gap in the literature as the measurements methods that have been used to date may have prompted the participants to self-handicap.

\section{Possible Influences of Methods of Assessment on Claimed Self-Handicapping}

Self-handicapping has been explored as a trait (e.g., Lung, Chia-Huei, Ying, MengShyan, \& Shang-Hsueh, 2009; Ommundsen, 2001, 2004), a state (e.g., Finez \& Sherman, 2012; Kuczka \& Treasure, 2005; Martin \& Brawley, 2002), and both (e.g., Carron, Prapavessis, \& Grove, 1994; Hirt et al., 1991; Ryska, Yin, \& Cooley, 1998). Regarding selfhandicapping conceptualized as a state, several studies have used a scale with a list of several impediments (e.g., Coudevylle, Gernigon, \& Martin Ginis, 2011; Coudevylle, Martin Ginis, Famose, \& Gernigon, 2008b; Coudevylle et al., 2009; Standage et al., 2007; Martin \& Brawley, 2002). Other studies (for a review, Coudevylle, Gernigon, Martin Ginis, \& Famose, in press; Prapavessis, Grove, \& Eklund, 2004) have employed an "open-ended" response format similar to that of Carron et al. (1994), who asked male athletes from a variety of team sports to list any events that had disrupted their preparation for competition during the past week. Prapavessis and colleagues (2004) classified the cited obstacles and observed that those most frequently cited were school activities/commitments (30.5\%) and physical state/injury/illness (20.5\%), which tend to be situational, uncontrollable, and/or socially desirable. The least frequently cited impediments were personal problems (4.9\%) and conflicts with teammates or coaches $(3.7 \%)$.

It seems reasonable to assume that proposing a list of potential impediments and asking participants which ones pertain to them could actively push them into selfhandicapping. This method could prompt participants to indicate impediments that they might not mention without this invitation and, moreover, this type of question may favor social desirability bias. In order to avoid influencing participants toward self-handicapping, it seems 
important to remain neutral, which could be achieved by asking them to indicate any "reasons (and not impediments) that would explain their ongoing good (and not only bad) or bad performance."

\section{Possible Influences of Environmental Context on Claimed Self-Handicapping}

To be compared, two experimental situations should differ only by the independent variable. Motivational climate may be a possible claimed self-handicap (Carron et al., 1994, Ferrand, Tetard, \& Fontayne, 2006), which suggests the need to standardize this parameter between sessions to prevent differential bias in comparisons of two experimental conditions. However, previous studies on the influence of motivational climate on self-handicap have not addressed this methodological constraint (e.g., time of day, temperature, hygrometry, ventilation, light). The two experimental studies showing that claimed self-handicaps are used more in PMC than MMC (Coudevylle et al., 2009; Standage et al., 2007) used methods that could reasonably be thought to stimulate self-handicapping. They also did not report high standardization of conditions between experimental sessions. Therefore, the main purpose of the present study was to determine whether the use of claimed self-handicaps - assessed using non-influencing open-ended questions_-would differ across experimentally manipulated motivational climates in a strictly controlled environment. Our general hypothesis was that engagement in self-handicapping is increased in PMC relative to MMC. In this quantitative study, we tested the following hypotheses: the PMC condition is associated with (a) a greater number of reported impediments, (b) a greater number of impediments per reporter, and (c) a higher perceived impact of the reported impediments on possible failure in a motor task than the MMC condition.

\section{Qualitative Approach in Self-Handicapping Strategies in Tropical Climate}

The experiment was conducted in the West Indies, which has a tropical climate (i.e., hot, wet climatic environment). This climate is known to be deleterious for aerobic exercise 
1 (Galloway \& Maughan, 1997; Hue, 2011; Morris, Nevill, Lakomy, Nicholas, \& Williams,

2 1998) but does not have a negative influence on anaerobic exercise (Racinais, Blonc,

3 Jonville, \& Hue, 2005; Racinais et al., 2006). Some of the studies on the impact of the

4 tropical climate on performance have suggested that a hot environment modulates several

5 psychological factors, including mood (McMorris et al., 2006) and complex (Gaoua,

6 Grantham, Racinais, \& Massoui, 2012) and simple (Cian, Barraud, Melin, \& Raphel, 2001)

7 cognitive performance, which suggests a psychological component of thermal discomfort in

8 this climate. Physiological research has shown that aerobic exercise performance is decreased

9 in the tropical environment (Galloway \& Maughan, 1997; Hue, 2011; Morris et al., 1998) and

10 that the pain and thermal discomfort associated with exercise is increased. However, it seems

11 reasonable that people in an original situation encouraging comparisons of one's own

12 performance relative to others feel their ego threated (e.g., performance motivational

13 climate), which might lead them to protect themselves with a strategy of overstating

14 impediments. If this is so, perceptions of discomfort and painfulness could be overestimated

15 in a tropical climate. We therefore investigated the nature of the self-handicaps in a physical

16 test performed in hot and wet environment. Using a qualitative approach, the second purpose

17 of the present study was to provide information about the nature of self-handicapping claimed

18 in a physical test in hot-wet climatic environment. We gave particular attention to the

19 hypothesis that tropical climate would be claimed more often in PMC than MMC, which

20 would be interesting in our experimental setting as the participants were all acclimated.

\section{Methodology}

22 Participants

Seventy physical education students ( $M_{\text {age }}=19$ years; age range: $18-20$ years), 45 men and 25 women, participated in the study after giving written consent. All were Guadeloupian 
session, the goal was presented (mastery vs. performance, see procedure section); the participants then all underwent two measures to assess their personal investment in the experimental task and its outcome. First, they answered a question on the importance of accomplishing the task on a 7-point Likert-type scale ranging from 1 ("not at all important") to 7 (“completely important"). Second, they answered a question on their intention to do their best to achieve the task-related goal presented on a 7-point Likert-type scale ranging from 1 ("not at all agree") to 7 (“completely agree"). In line with the methodology of previous studies (e.g., Hausenblas \& Carron, 1996; Carron, Prapavessis \& Grove, 1994), we removed those participants who reported low perceived event importance from the data analyses. Only the participants who scored at least " 4 " on both measures were included in the present study. Of the 70 participants, 9 participants did not meet the inclusion criteria and were excluded from the study.

\section{Measures}

The questions were interviewer-administered. Participants were asked individually if there were any reasons that would explain their potentially good or bad future performance (yes/no). If yes, they were asked to name them, and they were then asked to identify the extent to which each reason could promote or impair their performance by using a Likert-type scale ranging from -4 ("completely harmful") to +4 ("completely helpful"). This measure was named "perceived impact." After answering each question, the participants were asked to verify what the interviewer had written on the questionnaire. Then, an individual score of impediment reporting was obtained by calculating the sum of these extents. Higher scores were indicative of greater reports of performance impediments. This measure has been used in previous studies involving competitive athletes (e.g., Carron et al., 1994; Ryska et al., 1998) but by asking to indicate any "reasons (and not impediments) that could explain their ongoing good (and not only bad) or bad performance." We then calculated the mean number 
of impediments reported by all the participants and by only the impediment reporters. Participants reporting at least one impediment to performance were categorized as impediment reporters.

\section{Experimental Task}

We worked with physical education students, some of whom were aware of the deleterious effect of tropical climate on aerobic performance. We therefore expected that they would be pushed into claiming aerobic exercise in a tropical environment as a potential impediment. To avoid this, we chose an anaerobic exercise, as we assumed it would be less likely to encourage them to claim the tropical climate as a reason for potential failure. They individually performed an isometric maximal voluntary contraction in a handgrip task. This task is mainly anaerobic and has the advantage of simplicity and high reproducibility. Thus, the participants maintained a 70\% maximal voluntary contraction until exhaustion. During this contraction, participants were graphically informed of the force they were producing on a laptop screen. With regard to inter-individual comparisons, this type of exercise precludes bias caused by differences in the force production observed between the sexes. Electromyograms (EMG) were obtained using MP30 equipment (Biopac Systems, Inc., Santa Barbara, CA) and BSL Pro Version 3.6.7 software (Biopac Systems, Inc.). Electrical activity was recorded with two surface electrodes.

\section{Procedure}

The experiment was conducted during a regularly scheduled class. A crossover design was used, with all participants completing the procedure with a two-week interval between sessions, one in PMC and one in MMC. The conditions were presented in randomized order for all participants. All participants were living in the West Indies, which has a tropical climate (i.e., hot, wet climatic environment) characterized by consistently high monthly temperatures, often exceeding $18^{\circ} \mathrm{C}$ throughout the year, and rainfall that exceeds 
evapotranspiration for at least 270 days per year (Hue, 2011; Salati, Lovejoy, \& Vose, 1983). Thus, the tropical environment was strictly monitored in both sessions to standardize the experimental conditions. In the experimental room, the ambient temperature was $30.7^{\circ} \mathrm{C}( \pm$ $0.9 S D)$ and the humidity was $70.0 \%( \pm 3.6 S D)$, and this environment was maintained by electric heating and kettle systems. The ambient light was artificial and strictly the same (fluorescent light $4000 \mathrm{~K}$ ), and the ventilation was null. The time spent by each participant was set to $20 \mathrm{~min}$.

Performance motivational climate (PMC) test condition. To increase the likelihood of self-handicapping strategies, we set a PMC (Coudevylle et al., 2009; Standage et al., 2007). To do so, we emphasized results by encouraging comparisons of one's own performance relative to others, which is conceptualized as a "normative comparison". The use of self-handicaps and of the performance has been realized in front of an audience (Ames \& Archer, 1988; see Elliot, Cury, Fryer, \& Huguet, 2006). During this session, participants were told that their results for the experimental task (time at $70 \%$ of maximal) would be used to establish a public ranking. To emphasize the importance of this ranking and thus increase the likelihood of self-handicapping strategies, we explicitly underlined that this would lead to the identification of the best and worst students at the university for this task. Then, participants completed the measures of claimed self-handicapping strategies. In order to hide the true purpose of the self-handicapping questionnaire, the experimenter told the participants: "The following questionnaire is intended to determine your actual state right now in order to interpret your results today. It will allow those who evaluate your competence (the other students) to consider your current personal situation when authenticating your results and comparing them with those of the other participants."

Mastery motivational climate (MMC) test condition. In the MMC condition, participants were told that their results on the performance task, as well as the claimed 
reasons for potential failure and success, would not be made public. We particularly insisted that comparisons would not be made between their scores and those of classmates. They then completed the measures of claimed self-handicapping strategies. In both sessions, the participants performed the experimental task after completing the claimed self-handicapping measures. After the second session, all students were told the true purpose of the study and about self-handicapping strategies. The procedure was similar to that employed in previous studies of self-handicapping (see Coudevylle, Martin Ginis, \& Famose, 2008a; Coudevylle et al., 2008b; Coudevylle et al., 2009). climate condition on the reporting of (a) any impediment, and then (b) impediments that were reported in both sessions, in the whole sample, and in impediment reporters. We then performed Student's t tests for paired samples to test for differences across conditions in (a) the number of reasons reported, and in (b) the score of impediment reporting in the whole sample, in impediment reporters, and in participants who reported impediments in both sessions. Last, a Student's $t$ test was used to analyse the differences between the mean importance of impediment reported and the performance climate condition in the participants who reported impediments in both sessions.

The second purpose of this study was to provide information about the nature of selfhandicapping claimed in a physical test in hot, wet environment using a qualitative approach. Categories of impediments were constructed following a methodology presented elsewhere (Ferrand et al., 2006) and based on the principle of triangulation described by Patton (2002). We first performed investigator triangulation by analysing the data at three authors; we then performed theory triangulation by including in the analysis an author outside of the particular field of the study. The authors, after reading and re-reading the questionnaires, independently 
identified raw items, which better described the reasons reported by the participants for selfhandicapping. Then, the authors discussed these edited items until they reached full agreement. Raw items were then combined into low-order themes until agreement was reached. Then, the low-order themes were combined into high-order themes, and the latter were grouped into categories. In the analysis process, a researcher who was not a study author, but who was knowledgeable about qualitative approaches, was included to criticize and discuss the categorizations. After reaching full agreement from all members, the categories were validated. McNemar's Chi square tests were conducted to analyse the qualitative data.

\section{Results}

The results are presented as follows: quantitative analyses of the use of claimed selfhandicapping, followed by qualitative examination of the nature and type of claimed selfhandicapping in a hot, humid environment.

\section{Quantitative Analyses of Claimed Self-handicapping}

The first set of analyses aimed at determining whether the use of claimed selfhandicapping strategies varied between the PMC and MMC conditions. Fifty-two participants $(74.3 \%)$ reported at least one reason that could have modulated their performance in at least one session. Four participants reported only reasons for a good performance in the MMC condition (one for each). Three reported only reasons for a bad performance in the PMC condition, and only one participant reported only reasons for a good performance in both conditions. One participant reported one reason for a bad performance in the MMC condition and one reason for a good performance in the PMC condition. Thirty-six participants $(51.4 \%)$ reported at least one reason for bad ongoing performance in the MMC condition, whereas 47 $(67.2 \%)$ did in the PMC condition (Table 1). 
condition and not in the PMC condition was very low (Figure 1). The number of participants who did not report impediment in the MMC condition and did in the PMC one was more than five times higher (Figure 1). Also, the number of impediments reported was increased in the performance climate condition when we took into account the whole group, only impediment reporters, and only participants who reported in both sessions (Table 2). The maximum number of impediments reported was three in both sessions.

The higher mean perceived impact of impediments observed in the PMC condition was not significantly different from the impact observed in the MMC session in participants who reported them in both sessions (Table 2). The maximum perceived impact of impediments reported was three in both sessions. However, the score of impediment reporting was found to be associated with the condition, and with participants reporting higher scores in the performance condition in the whole sample, the impediment reporters, and the participants who reported in both sessions (Table 2). The maximum selfhandicapping score was six in the MMC and eight in the PMC.

\section{Qualitative Analyses of Claimed Self-handicapping}

The second set of analyses aimed at providing information on the use of selfhandicapping strategies in a physical test performed in a hot, wet environment. Reasons reported for poor ongoing performance, frequencies and perceived impacts according to motivational climate conditions are presented in Table 3. Two categories (internal and external impediments), three high-order themes (physical state, mental state and environment), six low-order themes and 14 items were edited, requiring some recodifications. One example of these recodifications is presented for each item in the same table. 
The purpose of the present study was to quantitatively and qualitatively examine whether claimed self-handicapping is increased in a performance motivational climate (PMC) compared with a mastery motivational climate (MMC) in a hot, humid testing situation.

\section{Quantitative Analyses of Claimed Self-handicapping}

The first aim of the present study was to test the hypothesis that self-handicapping strategies are used more in PMC than in MMC in a controlled environment and using noninfluencing open-ended questions. Our results support this hypothesis. Three working hypotheses were investigated. Two of them were validated while the third was only partially validated.

In accordance with the first working hypothesis, the number of reported impediments increased in the PMC compared with the MMC condition. This finding is consistent with previous works (Coudevylle et al., 2009; Standage et al., 2007) and supports the idea that PMC stimulates claimed self-handicapping. It is thought that PMC tends to threaten the self through social comparisons and risks to out perform others (Ames \& Archer, 1988). We tried to increase the saliency of these characteristics of PMC through the presentation of the experimental task. It is thus interesting to observe that only $7.5 \%$ of the participants who reported impediments in MMC did not report them in PMC, whereas $40.0 \%$ of the participants who did not report impediments in MMC became self-handicap users in PMC (see Figure 1).

In accordance with the second working hypothesis, the number of impediments per participant was higher in PMC than MMC. It is interesting to observe that not only did nearly half of the non-reporters in MMC became reporters in the PMC climate, but also that the number of reported impediments increased in PMC in the whole sample, in the impediment reporters, and in the participants who reported in both sessions. The number of reported impediments consequently seemed to be a way for participants who had already claimed self- 
handicaps in MMC to better protect themselves in the more self-threating performance climate. This finding is important because it suggests that self-handicapping may not be a binary strategy but more complex, with people self-handicapping proportionally to the perceived importance of the threat to self. Conversely to the study of Coudevylle and colleagues and others (e.g., Standage et al., 2007), the present study did not present participants with a list of possible handicaps, asking them to indicate if any of them would be likely to impair performance. It is possible that doing so would push participants to indicate self-handicaps that they might not have suggested on their own, thereby artificially increasing the number of impediments reported. Such a methodology would be biased, exploring not the way people spontaneously engage in self-handicapping but the way they engage in selfhandicapping when they are prompted to do so.

In comparison with other studies (e.g., Carron et al., 1994; Ryska et al., 1998) using a similar methodology, we attempted to avoid influencing participants to self-handicap. Indeed, the participants were asked to indicate any "reasons (and not impediments) that could explain their ongoing good or bad (and not only bad) performance." While it is not possible to demonstrate that this methodological difference alone explains the low number of impediments reported, it may have contributed.

The third working hypothesis was only partially validated. Although the perceived impact of impediments was higher in the PMC condition, this difference was not significant. It is reasonable to assume that a bigger sample might have shown significance. It remains interesting to observe that to improve their self-protection, the participants who were already engaged in self-handicapping strategies seemed to multiply the number of reported impediments rather than increase their mean perceived impact, which led to significantly greater self-handicapping scores. This result is original as Coudevylle and colleagues (2009) failed to statistically demonstrate an increase in the self-handicapping score in PMC, despite 
differences observed in their study sample. This could be explained by a statistical power difference probably due to different sample sizes (31 vs. 52).

\section{Qualitative Aspects of Claimed Self-handicapping}

We investigated the nature of the self-handicaps reported prior to a physical test in a

5 hot, wet environment. As this part of the study was exploratory, no hypotheses were advanced. However, we conducted a statistical analysis to explore the association of motivational climate with each item, low-order theme, high-order theme and category. The inductive categorization of reported impediments suggested only one significant result. The number of internal impediments reported significantly increased in PMC. The number of external impediment reporters also increased in PMC, but not to a significant extent. Thus, it is difficult to draw conclusions on a hypothetical qualitative shift in self-handicapping strategies across motivational climates. However, it is interesting to observe that reported impediments have tended to vary between studies. The first low-order theme was the impediments related to fatigue. This impediment was the most reported in the present study, whereas it was not mentioned by Prapavessis et al. (2004) nor reported by Ferrand et al. (2006). In the present experimental context, the participants claimed "heat" and "stuffiness" as possible external reasons that could impair their performance. These impediments related to tropical climate were less numerous than those related to internal obstacles. This could be explained by the fact that the participants lived in a tropical environment all year long, making tropical conditions less salient potential impediments than for people living in a neutral climate. These impediments are different from what has been previously found in the self-handicap literature. This inconsistency seems to indicate that there is no impediment that is always cited but that participants choose the first obstacles that come to mind. This would explain why the impediments related to the tropical climate were not reported more often: the participants opted for internal impediments, hardly verifiable whatever the context. 


\section{Conclusion}

The present study aimed at testing the hypothesis that the use of claimed selfhandicaps differs across experimentally manipulated motivational climates, in a controlled environment and using non-influencing open-ended questions. Overall, the present research demonstrated that in the physical activity context, (a) participants who engage in a selfhandicapping strategy were more numerous, (b) the number of self-handicaps reported so as the self-handicap score was greater, and (c) the participants who engaged in a selfhandicapping strategy in both sessions reported more impediments in the PMC condition than in the MMC condition. It seems that the increased engagement in a self-handicapping strategy in PMC was mediated by an increase of the number of reported impediments rather than an increase in the perceived impact of these last. The quantitative differences observed in the present study relative to previous studies might be due to differences in the methodological approach, which suggests the interest of designing a study on the impact of methodological choices on self-handicapping involvement. The main limitation of the present study is the relatively moderate sample size, which may explain the non-significant effect of motivational climate on the perceived impact of impediments. Another limitation is that we did not assess perceptions of the motivational climate, although Midgley and Urdan (2001) showed that these perceptions influence self-handicapping. It is reasonable to assume that a preliminary screening of only participants who perceived PMC as a PMC and MMC as an MMC would have modulated the results, increasing the association of claimed selfhandicapping with the motivational climate.

In future research, it may be helpful to conduct a mixed physiological/psychological study. Some studies suggest that a hot environment modulates several psychological factors, such as mood (McMorris et al., 2006) and complex (Gaoua et al., 2012) and simple (Cian et al., 2001) cognitive performance. This suggests the hypothesis of a psychological component 
1 of thermal discomfort in tropical climate. In the field of physiological research on the impact of the tropical climate on performance, it might therefore be relevant to consider that the selfreported weight of climate, as an impediment, may be modulated by a tendency toward self-

$4 \quad$ handicapping strategy when the self is threatened, as may occur in competition or

5 experimental work. Indeed, aerobic exercise performance is decreased in a tropical environment (Galloway \& Maughan, 1997; Hue, 2011; Morris et al., 1998) but it is possible that this claim is overstated by some athletes for self-protection or self-enhancement.

From an applied perspective, it is important to develop an MMC to promote personal

9 progress (e.g., Gernigon, d'Arripe-Longueville, Debove, \& Puvis, 2003). Teachers who are aware of the scientific literature favor an MMC to encourage progress. However, students have their own goals. Despite the MMC set by the teacher, students with performance goals may very well remain focused on their performance goals. Urdan (2004) examined how students perceive and interpret achievement goal messages in the classroom. Knowledge of

14 the strong relationship between PMC and self-handicapping might give teachers another 15 reason to control the climate they propose to their class. Assessing self-handicapping rather than the motivational climate would avoid the social desirability effect by which students

17 declare that they are seeking a mastery goal when in fact they are seeking a performance goal. Thus, a student's declaration of obstacles while supposedly in an MMC setting could be an indicator that he or she actually perceives a PMC anyway. 


\section{References}

Ames, C. A. (1984). Achievement attributions and self-instructions in competitive and individualistic goal structures. Journal of Educational Psychology, 76(3), 478-487. doi: $10.1037 / 0022-0663.76 .3 .478$

Ames, C. A. (1992). Achievement goals, motivational climate, and motivational processes. In G. C. Roberts (Eds.), Motivation in sport and exercise (pp. 161-176). Champaign, IL: Human Kinetics.

Ames, C. A., \& Archer, J. (1988). Achievement goals in the classroom: Students' learning strategies and motivation processes. Journal of Educational Psychology, 80(3), 260267. doi: $10.1037 / 0022-0663.80 .3 .260$

Berglas, S., \& Jones, E. E. (1978). Drug choice as a self-handicap strategy in response to non contingent success. Journal of Personality and Social Psychology, 36(4), 405-417. doi: $10.1037 / 0022-3514.36 .4 .405$

Carron, A. V., Prapavessis, H., \& Grove, J. R. (1994). Group effects and self-handicapping. Journal of Sport and Exercise Psychology, 16, 246-257.

Cian, C., Barraud, P. A., Melin, B., \& Raphel, C. (2001). Effects of fluid ingestion on cognitive function after heat stress or exercise-induced dehydration. International Journal of Psychophysiology, 42(3), 243-251. doi: 10.1016/S0167-8760(01)00142-8

Coudevylle, G. R., Gernigon, C., \& Martin Ginis, K. A. (2011). Self-esteem, self-confidence, anxiety and claimed self-handicapping: A mediational analysis. Psychology of Sport and Exercise, 12(6), 670-675. doi: 10.1016/j.psychsport.2011.05.008

Coudevylle, G. R., Gernigon, C., Martin Ginis, K. A., \& Famose, J.-P. Les Stratégies d'autohandicap : Fondements théoriques, déterminants et caractéristiques [Selfhandicapping strategies: theoretical foundations, determinants, and characteristics]. Psychologie française, article in press. doi: 10.1016/j.psfr.2014.04.002 
Coudevylle, G. R., Martin Ginis, K. A., \& Famose, J.-P. (2008a). Determinants of selfhandicapping strategies in sport and their effects on athletic performance. Social Behavior and Personality, 36(3), 391-398. doi: 10.2224/sbp.2008.36.3.391

Coudevylle, G. R., Martin Ginis, K. A., Famose, J.-P., \& Gernigon, C. (2008b). Effects of self-handicapping strategies on anxiety prior to athletic performance. The Sport Psychologist, 22, 304-315.

Coudevylle, G. R., Martin Ginis, K., Famose, J.-P., \& Gernigon, C. (2009). An experimental investigation of determinants and consequences of self-handicapping strategies across motivational climates. European Journal of Sport Science, 9(4), 219-227. doi: $10.1080 / 17461390902780437$

Dweck, C. S. (1986). Motivational processes affecting learning. American Psychologist, 41(10), 1040-1048. doi: 10.1037/0003-066X.41.10.1040

Elliot, A. J., Cury, F., Fryer, J. W., \& Huguet, P. (2006). Achievement goals, selfhandicapping, and performance attainment: A mediational analysis. Journal of Sport \& Exercise Psychology, 28, 344-361.

Ferrand, C., Tetard, S., \& Fontayne, P. (2006). Self-handicapping in rock climbing: A qualitative approach. Journal of Applied Sport Psychology, 18, 271-280.

Finez, L., \& Sherman, D. K. (2012). Train in vain: the role of the self in claimed selfhandicapping strategies. Journal of Sport \& Exercice Psychology, 34, 600-620.

Galloway, S. D., \& Maughan, R. J. (1997). Effects of ambient temperature on the capacity to perform prolonged cycle exercise in man. Medecine Science in Sports and Exercise, $29,1240-1249$.

Gaoua, N., Grantham, J., Racinais, S., \& Massoui, F. (2012) Sensory displeasure reduces complex cognitive performance in the heat. Journal of Environmental Psychology, 32, $158-163$. 
Gernigon, C., d'Arripe-Longueville, F., Debove, V., \& Puvis, A. (2003). Situational indexes of achievement motivation, help-seeking, and performance: Influences of the learning context and gender differences. Research Quarterly for Exercise and Sport, 74, 473479. doi: $10.1080 / 02701367.2003 .10609117$

Hausenblas, H. A., \& Carron, A. V. (1996). Group cohesion and self-handicapping in female and male athletes. Journal of Sport and Exercise Psychology, 18, 132-143.

Hirt, E. R., Deppe, R. K., \& Gordon, L. J. (1991). Self-reported versus behavioral selfhandicapping: Empirical evidence for a theoretical distinction. Journal of Personality and Social Psychology, 61, 981-991. doi: 10.1037/0022-3514.61.6.981

Hue, O. (2011). The challenge of performing aerobic exercise in tropical environments : Applied knowledge and perspectives. International Journal of Sports Physiology and Performance, 6, 443-454.

Kuczka, K. K., \& Treasure, D. C. (2005). Self-handicapping in competitive sport: Influence of the motivational climate, self-efficacy, and perceived importance. Psychology of Sport and Exercise, 6, 539-550. doi: 10.1016/j.psychsport.2004.03.007

Leary, M. R., \& Shepperd, J. A. (1986). Behavioral self-handicapping vs. self-reported handicaps: A conceptual note. Journal of Personality and Social Psychology, 51(6), 1265-1268. doi: 10.1037/0022-3514.51.6.1265

Lung, H. C., Chia-Huei, W., Ying, H. K., Meng-Shyan, L., \& Shang-Hsueh, S. (2009). Fear of failure, $2 \times 2$ achievement goal and self-handicapping: An examination of the hierarchical model of achievement motivation in physical education. Contemporary Educational Psychology, 34, 298-305.

Martin, K. A., \& Brawley, L. R. (2002). Self-handicapping in physical achievement settings: The contributions of self-esteem and self-efficacy. Self and Identity, 1(4), 337-351. doi: $10.1080 / 15298860290106814$ 
McMorris, T., Swain, J., Smith, M., Corbett, J., Delves, S., Sale, C., Harris, R. C., \& Potter, J. (2006). Heat stress, plasma concentrations of adrenaline, noradrenaline, 5hydroxytryptamine and cortisol, mood state and cognitive performance. International Journal of Psychophysiology, 61, 204-215.

Midgley, C., \& Urdan, T. (2001). Academic self-handicapping and achievement goals: A further examination. Contemporary Educational Psychology, 26, 61-75.

Morris, J. G., Nevill, M. E., Lakomy, H. K. A., Nicholas, C., \& Williams, C. (1998). Effect of a hot environment on performance of prolonged, intermittent, high-intensity shuttle running. Journal of Sports Sciences, 16, 677-686.

Nicholls, J. (1989). The competitive ethos and democratic education. Cambridge, MA: Harvard University Press.

Ntoumanis, N., Thøgersen-Ntoumanis, C., \& Smith, A. (2009). Achievement goals, selfhandicapping, and performance: A 2 × 2 achievement goal perspective. Journal of Sports Sciences, 27(13), 1471-1482. doi: 10.1080/02640410903150459

Ommundsen, Y. (2001). Self-handicapping strategies in physical education classes: The influence of implicit theories of the nature of ability and achievement goal orientations. Psychology of Sport and Exercise, 2(3), 139-156. doi: 10.1016/S14690292(00)00019-4

Ommundsen, Y. (2004). Self-handicapping related to task and performance-approach and avoidance goals in physical education. Journal of Applied Sport Psychology, 16(2), 183-197. doi: 10.1080/10413200490437660

Patton, M. Q. (2002). Qualitative Research and Evaluation Methods. Thousand Oaks, CA: Sage Publications.

Prapavessis, H., Grove, J. R., \& Eklund, R. C. (2004). Self-presentational issues in competition and sport. Journal of Applied Sport Psychology, 16, 19-40. 
Racinais, S., Blonc, S., Jonville, S., \& Hue, O. (2005). Time of day influences the environmental effect on force and contractility. Medecine \& Science in Sports \& Exercise, 37, 256-261.

Racinais, S., Chamari, K., Hachana, Y., Bartagi, Z., Blonc, S., \& Hue, O. (2006). Effect of an accute hot and dry exposure in moderately warm and humid environment on muscular performance at different time of day. International Journal of Sports Medecine, $27,49-54$.

Ryska, T. A., Yin, Z. N., \& Cooley, D. (1998). Effects of trait and situational selfhandicapping on competitive anxiety among athletes. Current Psychology, 17, 48-56.

Salati, E., Lovejoy, T. E., Vose, P. B. (1983). Precipitation and water recycling in tropical rain forests with special reference to the amazon basim, Environmentalist, 3, 67-72.

Snyder, C. R., \& Smith, T. W. (1982). Symptoms as self-handicapping strategies: The virtues of old wine in a new bottle. In G. Weary (Eds.), Integrations of Clinical and Social Psychology (pp. 104-127). New York: Oxford University Press.

Standage, M., Treasure, D. C., Hooper, K., \& Kuczka, K. (2007). Self-handicapping in school physical education: The influence of the motivational climate. British Journal of Educational Psychology, 77(1), 81-99. doi: 10.1348/000709906X103636

Tice, D. M. (1991). Esteem protection or enhancement? Self-handicapping motives and attributions differ by trait self-esteem. Journal of Personality and Social Psychology, 60(5), 711-725. doi: 10.1037/0022-3514.60.5.711

Urdan, T. (2004). Using multiple methods to assess students' perceptions of classroom goal structures. European Psychologist, 9, 222-231. http://dx.doi.org/10.1027/10169040.9.4.222

Urdan, T., \& Midgley, C. (2001). Academic self-handicapping: What we know, what more there is to learn. Educational Psychology Review, 13(2), 115-138. 